\title{
Educação de surdos numa perspectiva do Feminismo Negro
}

\author{
Deaf education from the perspective of Black Feminism
}

\section{Educación para sordos desde una perspectiva del Feminismo Negro}

\author{
Silvia Lúcia Lopes Benevides \\ silvialubenevides@gmail.com \\ Universidade do Estado da Bahia \\ Yuri Miguel Macedo* \\ yurimacedo@csc.ufsb.edu.br \\ Universidade Federal do Sul da Bahia \\ Universidade Federal do Espirito Santo \\ Daniela Adlay de Arruda Costa ${ }^{* * *}$ \\ danyadlay@hotmail.com \\ Universidade do Estado da Bahia
}

RESUMO: O presente artigo objetiva investigar como o tema gênero tem sido tratado nas pesquisas voltadas para a Educação de surdos. Realizou-se, para tanto, levantamento bibliográfico, na Scientific Electronic Library Online - SciELO e Google Scholar, de textos publicados entre 2008 e 2018, tendo por descritores de busca as palavras: "surdos", "surdez", "surda", "gênero", "sexualidade" e "sexo". Ficou demonstrado que as pesquisas na área da surdez tendem a considerar apenas os aspectos linguísticos do surdo. Mesmo quando se discute identidade surda, temas como etnia/raça, gênero, sexualidade e classe social são deixados em segundo plano ou sequer são mencionados. A população surda ainda está caminhando no sentido de ser reconhecida e de ter sua língua respeitada; provavelmente por isso, essas temáticas no âmbito das pesquisas educacionais tenham se revelado ainda pouco discutidas. É preciso considerar, entretanto, que a comunidade surda não é homogênea: existem interseccionalidades que podem incidir sobre a vida das pessoas que fazem parte dessa população. A discriminação sofrida por ser um sujeito surdo é agravada se somada ao racismo, machismo e a LGBTfobia. Tornam-se necessários estudos da sobreposição surdez-etnia/raça -

\footnotetext{
* Doutora e mestre em Educação pela Universidade Federal da Paraíba (2017), Especialização em Educação Especial pela Universidade Federal de Pernambuco(1994) e Graduação em Pedagogia pela Universidade do Estado da Bahia. Professora Adjunto da Universidade do Estado da Bahia.

Mestrando no Programa de Pós-Graduação em Ensino e Relações Étnico-Raciais da Universidade Federal do Sul da Bahia(UFSB), Professor no Programa de Pós-Graduação Lato Sensu Formação de Professores em Letras-Libras na Universidade do Estado da Bahia (UNEB) e Pesquisador do Núcleo de Estudos Afro-Brasileiros da Universidade Federal do Espirito Santo (UFES), licenciado em pedagogia.

Especialista em Docência do Ensino Superior pela Universidade Candido Mendes (2017), graduada em Ciências Contábeis pela Universidade do Estado da Bahia (2011) e graduanda em Pedagogia Bilíngue LIBRAS-Português pelo Instituto Nacional de Educação de Surdos.
} 
gênero e sexualidade no rol de interesses dos(as) pesquisadores(as) em Educação Especial e Inclusão para ressignificar concepções e práticas voltadas para a população surda que por muito tempo foi espoliada e cerceada de seus direitos.

PALAVRAS-CHAVE: Surdez. Educação de surdos. Gênero. Pedagogia Feminista.

ABSTRACT: This article aims to investigate how the theme of gender has been treated in research aimed at the education of the deaf. To this end, a bibliographic survey was carried out in the Scientific Electronic Library Online - SciELO and Google Scholar databases. We searched texts published between 2008 and 2018, using the following search words: "deaf," "deafness," "gender," "sexuality," and "sex." We found that research in the area of deafness tends to consider only the linguistic aspects of the deaf. Even when discussing deaf identity, issues such as ethnicity/race, gender, sexuality and social class are left in the background or are not even mentioned. The deaf population is still moving towards being recognized and having their language respected; probably for this reason, these themes in the scope of educational research have proved to be little discussed. It is necessary to consider, however, that the deaf community is not homogeneous. There are intersectionalities that can affect the lives of the people who are part of this population. The discrimination suffered by being a deaf person is aggravated if added to racism, sexism and LGBTphobia. It is necessary to study the overlap between deafness-ethnicity/race - gender and sexuality in the list of interests of researchers in Special Education and Inclusion in order to redefine concepts and practices aimed at the deaf population, which for a long time was stripped and curtailed of their rights.

KEYWORDS: Deafness. Deaf education. Gender. Feminist pedagogy.

RESUMEN: Este artículo tiene como objetivo investigar cómo se ha tratado el tema de género en la investigación dirigida a la educación de los sordos. Para este propósito, se realizó una encuesta bibliográfica en la Scientific Electronic Library Online - SciELO y Google Scholar durante los años 2008 a 2018, utilizando las palabras de búsqueda de la siguiente manera: "sordo"," sordo "," sordo "," género "," sexualidad "y" sexo ". Se ha demostrado que la investigación en el área de la sordera tiende a considerar solo los aspectos lingüísticos de los sordos. Incluso cuando se habla de identidad sorda, cuestiones como el origen étnico / raza, el género, la sexualidad y la clase social se dejan en un segundo plano o ni siquiera se mencionan. La población sorda todavía se está moviendo hacia el reconocimiento y el respeto de su idioma, probablemente por esta razón, estos temas en el ámbito de la investigación educativa han demostrado ser poco discutidos. Sin embargo, es necesario tener en cuenta que la comunidad sorda no es homogénea, existen intersecciones que pueden afectar la vida de las personas que forman parte de esta población. La discriminación sufrida por ser una persona sorda se agrava si se agrega al racismo, el sexismo y la fobia LGBT. Es necesario estudiar la superposición entre sordera, etnia / raza, género y sexualidad en la lista de intereses de los investigadores en Educación Especial e Inclusión para redefinir las concepciones y prácticas dirigidas a la población sorda, que durante mucho tiempo fue saqueada y rodeado de sus derechos.

PALABRAS CLAVE: Sordera. Educación para sordos. Género. Pedagogía feminista. ${ }^{1}$

\footnotetext{
${ }^{1}$ Agradecemos a Joaquim Lemos Ornellas pela tradução dos resumos.
} 


\section{Prologuemos}

Cada indivíduo acumula experiências distintas durante sua vida, as quais requerem adaptações e mudanças de comportamento diante das novas experiências e problemas (CORNACHIONE JR., 2004). Dessa forma, a educação constitui o suporte essencial para a formação de um cidadão, uma vez que fornece habilidades que o levam a utilizar o conhecimento, com condições de refletir, criticar e criar (ANDERE; ARAUJO, 2008).

Historicamente, a educação de surdos teve uma preocupação voltada para os meninos, em especial, os brancos das classes mais altas da sociedade. Para Brito (2019, p. 44), a escola possibilita "as condições para que as crianças e jovens das classes trabalhadoras sejam 'ensinadas' no melhor estilo da burguesia”. A entrada de meninas nas escolas foi uma conquista, especialmente para as mulheres surdas. A partir de então, cabe a seguinte problematização: A Educação de Surdos, no que diz respeito ao ensino ministrado às meninas e mulheres surdas, acompanhou as mudanças da Educação Regular?

No atual momento em que se encontra a sociedade brasileira, diversos padrões historicamente impostos vêm sendo questionados, daí emerge o protagonismo feminino na Educação. Apesar de a profissão docente ser majoritariamente feminina nos anos iniciais, ainda se educa meninas reproduzindo a lógica machista e patriarcal.

A população surda ainda está caminhando no sentido de ser reconhecida e de ter a sua língua respeitada. As questões de gênero e sexualidade, no seio do ambiente educacional, são ainda pouco discutidas abertamente. Por isso, esta pesquisa se torna relevante, pois, a partir dela, poderemos diagnosticar como o tema gênero tem sido tratado em pesquisas na área da Educação de surdos, por meio de um levantamento da quantidade e análise de artigos publicados nos últimos anos sobre a temática.

\section{História da Educação das meninas surdas}

O atual Instituto Nacional de Educação de Surdos (INES) foi a primeira instituição brasileira a se dedicar ao ensino formal de pessoas surdas. Fundado em 1856 na cidade do Rio de Janeiro, era chamado de Colégio Nacional para Surdos- 
Mudos de Ambos os Sexos. Embora o Colégio Nacional pretendesse educar tanto meninos quanto meninas surdas, como o próprio nome sugere, a Lei Geral sobre a Instrução Primária, de 1827, restringia o ensino das meninas apenas aos afazeres de casa sem nenhum embasamento pedagógico. O meio pelo qual foi possível driblar essa lei foi a nomeação da esposa do diretor Eduard Huet, responsável pela instrução das meninas surdas (WITCHS, 2017).

Uma questão que nos chamou a atenção é que, mesmo com essa responsabilidade, a professora das meninas, em nenhum dos trabalhos aos quais tivemos acesso, foi chamada pelo seu nome, mas pelo título de "esposa do Diretor Eduard Huet". Essa evidência, por si só, já revela o sexismo implícito na maioria dos trabalhos acadêmicos.

Alguns anos depois, em 1884, o novo diretor Tobias Leite, sob a alegação de que se a instituição trabalhasse com ambos os sexos haveria promiscuidade, proibiu a matrícula de meninas surdas (KLEIN; FORMOZO, 2008). As que já estavam matriculadas permaneceriam até a primeira menstruação e seriam devolvidas às suas famílias ou para abrigos (WITCHS, 2017). Dessa forma, aos poucos, o colégio voltaria a ser exclusivamente voltado ao público masculino. Para o diretor Tobias Leite, as meninas surdas poderiam ser educadas em casa, porque diferentemente dos meninos surdos, elas não causariam problemas à família, pois não se envolveriam com vícios. Por outro lado, aprenderiam, com os exemplos de outras mulheres da casa, a serem contidas e comedidas como deveriam ser.

Somente em 1932, no Governo Vargas, depois de uma enorme pressão de um grupo feminista chamado Aliança Nacional das Mulheres (ROCHA apud WITCHS, 2008), meninas surdas puderam, novamente, ser matriculadas no INES. No entanto, dessa vez, houve algumas restrições: funcionava em sistema apenas de externato, o que excluía o acesso das surdas residentes no interior do país, e apenas eram oferecidas oficinas de costura e bordado. Percebemos, assim, que o acesso à escola não garantia uma educação com equidade de gênero, mas a reprodução do sistema machista, mais uma vez perpetuado.

A primeira Instituição de Educação específica para meninas surdas foi o Instituto Santa Terezinha, fundada em 1929, pelas freiras Madre Luísa dos Anjos, Maria S. João, Magdalena da Cruz e Suzana Maria, que se especializaram na França e vieram se instalar em São Paulo. As meninas surdas de todo o país poderiam ser matriculadas em regime de internato ou externato e eram ensinadas a 
oralização, alfabetização e disciplinas do currículo de ensino primário de escolas regulares (TEIXEIRA, 2008). Ainda de acordo com Teixeira (2008), o ofício de transformar, por meio das práticas educativas, os alunos surdos em pessoas "úteis" à sociedade ficaria sob a responsabilidade das missionárias do Instituto.

Além das disciplinas do currículo, as meninas surdas deveriam aprender economia doméstica e os textos que estudavam com vistas à oralização, necessariamente, deveriam conter assuntos como utensílios domésticos, pois era esse o vocabulário que se esperava que elas usassem. Os momentos de lazer das meninas eram com aulas de dança e artesanato (TEIXEIRA, 2008). Novamente vemos que o acesso a uma escola, mesmo que só para meninas, não garantia uma educação libertadora, mas a manutenção do papel social da mulher feita para casar e cuidar de seu lar.

Assim, tanto no INES quanto no Instituto Santa Terezinha, pode-se perceber a desigualdade de ensino baseada no gênero, contribuindo para a manutenção do sistema de ensino em que privilegia os meninos com atividades mais dinâmicas e intelectuais, enquanto coloca as meninas numa situação de inferioridade, a quem só cabe o ambiente doméstico. Com o passar do tempo, a Educação de Surdos passa a aceitar ambos os sexos. No entanto, o foco está no mercado de trabalho, em sua maior parte. Ribeiro (2017) considera esta uma questão importante, pois o surdo inserido no mercado de trabalho tem sua autoestima e independência financeira garantida ou, pelo menos, viabilizada. Porém, a Educação de Surdos não tem se apresentado como um processo efetivo para formar cidadãos críticos e conscientes sobre questões tão importantes para a vida social.

De acordo com Ribeiro (2017, p. 180),

A subjetividade e formação do indivíduo é também essencial para a educação de surdos. A falta de comunicação e integração do surdo na comunidade e na sua própria família - quando a família é ouvinte - pode atrasar ou impedir a construção saudável de uma imagem de si e sua personalidade e, como nenhuma relação se dá sozinha, também a sua relação com os outros e com o mundo.

Percebemos, pois, que a dificuldade de comunicação do surdo com sua família o coloca em uma situação de limitação de aprendizagem. Temas polêmicos como sexualidade e gênero só serão desenvolvidos e aprendidos com colegas na escola, uma vez que, no processo formal de sala de aula, tais temas, muitas vezes, não são previstos nos currículos. 
Atualmente, as lideranças dos movimentos surdos no Brasil têm sido as mulheres. Klein e Formozo (2008) atribuem esse protagonismo das mulheres surdas à maior inserção delas no ensino superior e, por consequência, à docência. Assim, a influência no movimento surdo vem das escolas, pois para a comunidade funciona mais como um local de organização política do que um lugar para aprender.

A escola acaba por padronizar comportamentos de acordo com o discurso e as práticas pedagógicas vigentes, pois os professores e intérpretes que compõem aquela comunidade escolar são parte também da comunidade surda. Dessa forma, os estudantes surdos têm apoio para se organizar dentro das escolas pelas suas pautas de luta (KLEIN; FORMOZO, 2008).

\section{Revendo alguns conceitos}

Nas sociedades contemporâneas, capitalismo, sexismo, racismo, e LGBTfobia, dentre outras formas de opressão, não agem independentes. Segundo Sardenberg (2015), essas transversalidades, que autoras feministas chamam de interseccionalidades, mostram que mulheres de classe social mais baixa sofrem o sexismo de forma diferente de mulheres de classes mais ricas. Da mesma forma, mulheres negras sofrem o racismo, e mulheres brancas não; mulheres lésbicas ou trans experienciam questões de gênero e discriminação diferentemente de mulheres cisgêneras e heterossexuais. Assim, todas essas categorias precisam ser vistas e analisadas, pois classe, raça ou gênero não são matrizes estanques: elas se combinam de formas diferentes nas vidas de pessoas em uma comunidade.

Para Ribeiro (2016), refletir sobre interseccionalidade nos ajuda a compreender que não existe opressão que se sobreponha a outra e que, para combatê-las, é preciso romper com a estrutura, pois é uma questão estruturante da sociedade: "Ser oprimido não pode ser utilizado como desculpa para legitimar a opressão" (RIBEIRO, 2016, p. 101). A autora alerta para o não silenciamento dos grupos oprimidos e reafirma o quanto a interseccionalidade como aporte teórico do Feminismo Negro se faz muito necessário ao permitir uma prática que não negue identidades ou subordine outras.

O Feminismo Negro usa a interseccionalidade como ferramenta para pensar o mundo e a sociedade, seja em questões educacionais, econômicas, de saúde ou segurança, o que abrange o não acesso ou a não permanência de jovens negros na 
escola/universidade, a denúncia do genocídio da juventude, entre outros (RIBEIRO, 2016).

Gomes (1996), em sua pesquisa com professoras negras, mostra que, em geral, o racismo na escola pode não ser explícito, mas se faz presente no discurso. As professoras entrevistadas traziam uma história de vida em que o racismo foi vivenciado desde sua entrada na escola, ainda na infância, onde se viam sem referência de professores negros e submetidas a estereótipos sobre o papel da mulher negra em nossa sociedade e ensinamentos de que a felicidade e o sucesso eram para os brancos.

Na mesma pesquisa, Gomes (1996, p.76) observa, nos depoimentos, que muitas professoras negras foram discriminadas na escola quando crianças e se vê agora reproduzindo o discurso transmitido a ela desde o início de sua caminhada escolar, no curso de magistério e também no de pedagogia.

Ao se tornarem professoras, essas mulheres saíram do lugar, ora já designado pela sociedade, e ocuparam espaços sociais privilegiados, mas não demonstraram uma reflexão histórico-política sobre ser professora negra no Brasil, relações que precisam ser discutidas e refletidas na escola. Macedo, Oliveira e Peçanha (2019) explanam que a sangria do racismo deve ser estancada e que esse não se faz presente apenas no espaço escolar, mas é vinculado em toda a sociedade.

Em geral, as pesquisas na área da surdez levam em consideração apenas os aspectos linguísticos do surdo. Mesmo quando se discute identidade surda, temas como etnia/raça, gênero, sexualidade e classe social são deixados em segundo plano ou sequer são mencionados.

As pessoas surdas também encaram a discriminação de formas diversas em sua experiência de vida. A interseccionalidade revela que, por exemplo, uma mulher surda e negra pode enfrentar discriminações diferentes de uma mulher surda e branca, assim como uma pessoa surda e homoafetiva vivencia preconceitos diferentes de uma pessoa surda e heterossexual/heteronormativa. Todas essas experiências, também, são influenciadas pelas comunidades que fazem parte, incluindo a comunidade escolar.

$\mathrm{Na}$ Educação de Surdos, trata-se muito de um compartilhar a cultura linguística, como se não houvesse nenhuma outra influência na formação desse cidadão: ser surdo é apenas uma parte de sua identidade. Como ressalta Miranda 
(2017), o ouvintismo associado ao machismo ou ao racismo (ou a ambos) gera formas diferentes de discriminações. Mesmo dentro de uma escola bilíngue, é preciso considerar as vulnerabilidades internas do grupo, empoderar sujeitos que encaram formas específicas de preconceito e discriminação e, principalmente, os efeitos em sua aprendizagem escolar. Assim,

a educação de surdos deve ser dimensionada além de questões linguísticas e metodológicas; deve figurar no âmbito das discussões da educação com o um todo, levando em consideração, por exemplo, a promoção da igualdade racial e de gênero (MIRANDA, 2017, p. $65)$.

De acordo com Carvalho et al. (2017), a teoria feminista tem, como tema central, o conceito de gênero e busca, teórica e politicamente, mostrar a desigualdade entre os sexos. Dessa forma, fica evidenciada a opressão vivida pelas mulheres nos seus corpos durante a história da humanidade. Essa opressão, definida pelo termo sexismo, inferioriza as mulheres, mantendo os poderes e privilégios aos homens.

Gênero não se refere a sexo ou diferenças biológicas, mas a construções sociais e relações de poder, que desencadeiam em desigualdades e hierarquias. Trata-se de um fenômeno cultural que acontece na forma como as sociedades historicamente se organizam a partir dessas diferenças biológicas, definindo o que é ser masculino e feminino (SARDENBERG, 2011b). A delimitação do ser feminino e masculino define padrões que devem ser aceitos como inquestionáveis. Dentre estes, destacamos a (hetero)normatividade, que é entendida como caminho único, forma natural, a expressão legítima de expressão identitária e sexual (CARVALHO et al. apud SARDENBEG, 2011a).

Para Sardenberg (2011a), as abordagens de práticas educativas em sala de aula podem ser libertadoras tanto para mulheres como para homens, por meio de uma Pedagogia Feminista (ou Pedagogias Feministas), trazendo à tona uma crítica ao sistema patriarcal e machista que funciona na nossa sociedade. Através do trabalho pedagógico, é possível superar a desigualdade construindo uma nova sociedade com igualdade para os sexos. Na nossa visão, essa abordagem inclui também mulheres e homens que, além do sexo, tem a deficiência que os diferencia e hierarquiza entre eles. 
A educação numa perspectiva feminista propõe estratégias para romper com dualismos, como feminino/masculino, deficiência/capacitismo e subjetividade/ objetividade. Além disso, atém-se a vencer a lógica de que o conhecimento deve vir de uma fonte com autoridade para tal e que todas as vozes precisam ser ouvidas e valorizadas para a construção do conhecimento cooperativamente, apresentando-se como emancipatória e libertadora (SANTOS, 2012).

Dessa forma, não existe mais os "experts", mas todos e todas têm alguma sabedoria a compartilhar. Mesmo aquelas que tradicionalmente não seriam notadas ou não teriam voz podem se posicionar a respeito de algum assunto. A pedagogia feminista coloca o saber acadêmico e o saber pessoal em um mesmo plano, afirmando que o processo de aprendizagem ocorre com a interação de todos os sujeitos envolvidos (docentes e discentes) sem que apenas um detenha o poder de ensinar (LOURO, 1997).

\section{Educação de surdos numa perspectiva feminista}

O que se pode perceber é que a sala de aula se constitui de pessoas com personalidades e habilidades diversas, sejam elas quietas, agitadas, insensatas, responsáveis, dedicadas, desinteressadas, amigas, egoístas, entre outros. Isso não é definido pelo binarismo em que as meninas são sempre mais dóceis e os meninos agitados. O pluralismo da sala de aula deve ser entendido à luz da questão de gênero e do que é assimilado pela sociedade como comportamento feminino e comportamento masculino. Até mesmo no rendimento escolar é esperado um melhor desempenho para as meninas e não para os meninos.

A educação pode ser instrumento de transformação ou de manutenção de ideias antiquadas e de sistemas de opressão, pois é onde se aprende quais lugares podem ser ocupados na sociedade e por quem. No caso das pessoas surdas, por fazerem parte, em sua maioria, de famílias ouvintes, que não usam a língua de sinais, não aprendem sobre valores éticos, comportamento, saúde, sexualidade e assuntos polêmicos que são passados de pais/mães para filhos e filhas através da linguagem. Assim, seu primeiro contato com esses temas se dá na escola, pois lá é onde ocorre até mesmo a aquisição de sua língua natural.

A educação tem contribuído com a reprodução dessa visão de que as diferenças biológicas determinam papéis de homem (capaz, líder, assertivo, com 
qualidades superiores) e de mulher (submissa, subalterna, dócil, inferior) na sociedade. Se prestarmos atenção aos livros didáticos, em geral eles trazem essa visão por meio das personagens apresentadas e o que representam: personagens masculinos e brancos em posição de maior valor social, em detrimento a personagens femininas ou negras em posição de inferioridade (PASSOS et al., 2011). Personagens com deficiência, por sua vez, são muito pouco ou nenhuma vez mencionados.

De acordo com Gomes (1996), toda a comunidade escolar, sejam alunos, alunas, professores, professoras, pais, mães, tem suas identidades construídas de formas diversas através de suas histórias de vida pessoal e profissional. A escola tem papel importante nesse processo de formação, não só por meio do conhecimento também de identidades e personalidade e de como esses sujeitos irão perceber o mundo e seu relacionamento com os outros.

Essa escola não tem neutralidade; pelo contrário, ela convive com conflitos internos entre educadores, educadoras e educandos ou educandas. Não são conflitos apenas de classe, mas também de raça/etnia e gênero, pois são valores transmitidos pela escola aos estudantes (GOMES, 1996).

Os(as) surdos(as) têm experiências visuais que contribuem tanto para formação de personalidade quanto da construção de sua identidade, e sua interação social se dá por meio da língua de sinais. Entendemos, pois, que os surdos não precisam de cura, mas possuem uma diferença cultural baseada na forma de vivenciar suas experiências de vida (KLEIN; FORMOZO, 2008).

Uma proposta de educação de pessoas surdas baseada em uma Pedagogia Feminista se compromete em mostrar ao educando as possibilidades diversas de espaços a serem ocupados independentes de padrões. Uma pessoa surda não precisa ser uma cópia do ouvinte. Antes, deve perceber que existem relações de poder no discurso segundo o qual o seu desenvolvimento é lento ou que ela atrasa a turma, e que ela pode sim alcançar o aprendizado esperado desde que tenha suas especificidades consideradas.

Segundo Passos et al. (2011, p. 56),

Compete, portanto, ao/à educador(a) comprometer-se com uma educação sem julgamentos sobre a consciência do(a) educando(a), sem, muito menos, Ihe impor autoritariamente esse ou aquele modo de ver ou de se comportar em decorrência do seu sexo, raça ou classe social, por exemplo. Do mesmo modo, espera-se dele(a) a 
produção e a transmissão do conhecimento a todos(as), sem discriminação e sem o ocultamento do real que pode ocorrer, dentre outras situações, quando o conteúdo apresentado não responde às demandas dos(as) discentes, nem às necessidades sociais. Nesses casos, além de não ajudar os(as) alunos(as) a enfrentarem seus problemas concretos, os(as) distanciam do saber, pois fazem com que percam o interesse. [...] Entretanto, de forma geral, o conhecimento precisa ser um instrumento de poder e de transformação.

O (a) educando(a) precisa ser respeitado(a) em sua visão de mundo, levandose em conta sua experiência de vida, a comunidade da qual faz parte e, principalmente, como um ser autônomo e capaz para se desenvolver. Do mesmo modo, o(a) educador(a) deve ter sensibilidade para perceber os conflitos e preconceitos que esses(as) podem estar sofrendo em sala de aula, para que possa intervir de forma a garantir um entendimento entre eles(as), de equidade entre sexos, entre deficientes e não deficientes e entre culturas distintas às quais pertençam.

Dentro da escola, as diferenças precisam ser reconhecidas e respeitadas, e uma pesquisa que articule perspectivas antropológica e educacional permite que educando, educanda, professora, professor, negra, negro, branca e branco sejam considerados sujeitos sexuados, socioculturais. Rompe-se, assim, com o discurso colonial, hegemonizante, transmitido na escola, dando visibilidade ao outro na sua diferença (GOMES, 1996).

$\mathrm{O}(\mathrm{a})$ professor(a) precisa aguçar seu olhar aos processos de hierarquização e subordinação que se constróem em sala entre sujeitos (LOURO, 2011), sejam por motivo de orientação sexual, gênero, raça, deficiência ou outros. No campo teórico de uma educação feminista, no qual o campo central é a diferença, é simulado que todos os sujeitos são iguais, exercitam o poder com a mesma intensidade e dominam saberes que são igualmente legitimados e reconhecidos socialmente (LOURO, 1997).

Os(as) educandos(as) surdos(as), em sua diferença cultural e linguística, exercem poder e tem saberes a compartilhar com os ouvintes e vice-versa. Numa sala de aula feminista, as meninas surdas e os meninos surdos estão no mesmo patamar que meninas e meninos ouvintes, juntamente com o professor ou professora surdo(a) ou ouvinte que participa do processo. 
O processo de construção do conhecimento no âmbito escolar acontece paralelamente à formação da personalidade do estudante. Dessa forma, uma Pedagogia Feminista se empenha em uma transformação e inclusão social. Para isso, não encobre os conflitos numa postura de aceitação, mas promove um ambiente no qual as mulheres não precisam ser dóceis e submissas. Os(as) surdos(as) não precisam se ver como incapazes, mas tratados como seres conscientes e capazes de fazer escolhas de forma livre e responsável (PASSOS et al., 2017).

Dessa forma, discussões sobre violência doméstica, sexualidades, família, reprodução, profissionalismo, soberania popular, ética e moral, direitos, cidadania não podem ser ocultadas, porque fazem parte do dia a dia de estudantes e professores. Porém, numa prática pedagógica feminista, precisam ser discutidos com todos, sejam homens, mulheres, surdos, surdas, deficientes e não deficientes que façam parte da comunidade escolar. Klein e Formozo (2008) relatam situações tristes de mulheres surdas abusadas por homens ouvintes que não puderam denunciar por causa de dificuldades de comunicação com a família, e de outras que tiveram gestações indesejadas por falta de informações que poderiam vir do âmbito escolar.

A respeito do quanto as mulheres surdas estão suscetíveis à violência doméstica ou a outras agressões, não foram encontradas pesquisas no Brasil. No entanto, um estudo realizado nos Estados Unidos com 360 estudantes surdos trouxe informações relevantes: $48 \%$ dos entrevistados tinham experimentado carícias indesejadas, beijo, toque ou esfregação de suas áreas íntimas; $28 \%$ das mulheres tiveram algumas de suas roupas retiradas sem consentimento algum; relatos de vários atos sexuais não consensuais $(22 \%$, sexo oral; $19 \%$, sexo vaginal; $13 \%$, sexo anal); relatos de tentativas de sexo sem consentimento ( $14 \%$, sexo anal; $18 \%$, sexo vaginal; $27 \%$, sexo oral); $20 \%$ das mulheres admitiram já terem sido estupradas (FRANCAVILLO apud KRAUSE, 2017). Ainda Krause (2017) afirma que as mulheres surdas têm 1,5\% mais de chance de serem vítimas de agressão, assédio e violência doméstica que as ouvintes.

De acordo com Silva (2011), há uma contradição quando se fala dessas temáticas na escola: ou são silenciadas ou tratadas com preconceito, o que reforça a segregação de pessoas excluídas do exercício da cidadania no processo histórico, tais como as mulheres, homossexuais e negros, entre outros. 
Tendo em vista a abordagem dessas temáticas numa concepção feminista, é necessário que se escolha a metodologia mais efetiva para uma prática educativa não discriminatória. De acordo com Vanin (2011), deve-se, em primeiro lugar, avaliar - currículo de forma crítica, inserindo a temática de gênero e suas interseccionalidades, transversalmente, nos conteúdos a serem abordados. Skliar (apud KLEIN; FORMOZO, 2008) define o currículo escolar como “angustiante”, cujo foco é o homem ouvinte e branco. Ao se referir a surdos, o elaborador do currículo considera a expressão suficiente, desconsiderando outras diferenças entre eles.

Para isso, o segundo passo é a análise do material didático, que em nada favorece se trouxer, em textos ou ilustrações, situações que reforcem o sexismo, o racismo e a homofobia. Nesse caso, o ideal seria a substituição por outro material, fazendo-se uma análise crítica, pois alguns deles apenas colocam as figuras femininas ou negras ou deficientes de forma aleatória que, ao invés de romper estereótipos, reafirmam-nos (VANIN, 2011).

O ambiente escolar também precisa ser examinado criticamente para que o que seja discutido em sala reflita, por exemplo, nas decorações das programações e festas escolares, não estabelecendo hierarquia entre gêneros, raça/etnia, classe social ou sexualidade. O planejamento também deve ser feito, levando em consideração as experiências e vivências dos(as) educandos(as) para que a aula não seja desconectada do cotidiano. Para proporcionar uma reflexão crítica da realidade em que eles vivem, o ideal é utilizar situações-problema que eles vivenciem, a fim de que possam intervir de forma que respeitem as diferenças, sejam equânimes e gerem uma reelaboração e contextualização das ações, obtendo instrumentos de interpretação e atuação no contexto onde vivem (VANIN, 2011).

Louro (2011) chama a atenção para a questão do planejamento, que muitas vezes reforça a ideia do diferente ser estranho, quando o traz em foco apenas em datas e festas comemorativas. A prática de estabelecer um dia ou momento especial para dar visibilidade àqueles que não estão no foco do currículo é bastante incentivada. Por exemplo, o dia da mulher, do índio, da pessoa com deficiência, a semana da consciência negra, etc. muitas vezes apenas são celebrações da cultura do outro em momentos excepcionais, que sustentam a lógica do grupo dominante, pois é só nesses momentos que se leva em consideração a presença dessas identidades "marcadas". 
Aparentemente, a ambição de modificar o cotidiano da sala de aula é pequena, mas essa nova postura pode contribuir para uma reflexão sobre a sociedade. Ensinar a crítica e autocrítica é um legado do movimento feminista, bem como a rejeição de hierarquias impostas pelo sistema patriarcal capitalista e capacitista. (LOURO, 1997)

Todas essas ferramentas apresentadas podem ser utilizadas numa Escola Inclusiva ou Escola Bilíngue, pois Witchs (2017), em sua pesquisa sobre gênero e surdez, afirma que não encontrou diferenças nas questões de gênero e sexualidades entre escola de surdos e escolas regulares. Trazemos algumas sugestões de materiais que podem ser utilizados para abordagem dos temas: sobre gênero e diversidade, o filme $A$ fuga das galinhas; sobre masculinidade, o filme Como treinar seu dragão; sobre papéis sociais, o filme Mulan; sobre surdos e ouvintes, o filme $A$ cigarra surda $e$ as formigas; sobre a questão racial, o filme Branca de neve - Língua de Sinais.

\title{
5 Caminhos metodológicos
}

O presente estudo é de natureza bibliográfica, de caráter exploratório e seletivo, no que concerne ao material de pesquisa, possibilitando a determinação do material bibliográfico de interesse da pesquisa. Uma pesquisa bibliográfica, na perspectiva de Boccato (2006, p.266),

\begin{abstract}
Busca a resolução de um problema (hipótese) por meio de referenciais teóricos publicados, analisando e discutindo as várias contribuições científicas. Esse tipo de pesquisa trará subsídios para o conhecimento sobre o que foi pesquisado, como e sob que enfoque e/ou perspectivas foi tratado o assunto apresentado na literatura científica. Para tanto, é de suma importância que o pesquisador realize um planejamento sistemático do processo de pesquisa, compreendendo desde a definição temática, passando pela construção lógica do trabalho até a decisão da sua forma de comunicação e divulgação.
\end{abstract}

Um estudo bibliográfico consiste em um trabalho investigativo minucioso, por meio do qual se busca o conhecimento e a base fundamental para o todo de uma pesquisa. Assim, a elaboração da presente proposta de trabalho justifica-se, primeiramente, "pela intenção de torná-la um objeto facilitador do trabalho daqueles 
que possivelmente tenham dificuldades na localização, identificação de dados existentes por parte dos usuários" (PIZZANI et al., 2012).

Para a nossa coleta de dados, fizemos uma busca de artigos e periódicos publicados nas plataformas Scientific Electronic Library Online (SciELO) e Google Scholar (Google Acadêmico) durante os anos de 2008 a 2018, com enfoque que contemplasse o tema proposto no nosso objeto de pesquisa. Utilizamos as seguintes palavras de busca: "surdos", "surdez", "surda", "gênero", "sexualidade" e "sexo", com enfoque no lapso temporal de $2000-2018$.

\section{0 que encontramos/discussão}

Tanto na plataforma ScieLO como no Google Scholar não localizamos artigos e/ou periódicos cuja abordagem contemplasse a perspectiva de gênero e feminismo na Educação de Surdos. Dessa forma, fica evidenciado que não tem se dado a devida atenção às transversalidades que compõem a formação da personalidade dos surdos e os conflitos que vivenciam mesmo inseridos na comunidade surda.

A comunidade surda ainda é vista, no geral, como um grupo homogêneo que se identifica por meio da língua visogestual e de experiências visuais. No entanto, acreditamos que, assim como qualquer comunidade, existem os jogos e discursos de poder, os grupos hegemônicos e os privilégios que são obtidos seja pelo gênero ou classe social de cada pessoa.

Para Skliar,

A potencialidade de reconstrução histórica dos surdos sobre a sua educação e sua escolarização é, sem margem para dúvidas, um ponto de partida para uma reconstrução política significativa e para que participem, com consciência, das lutas dos movimentos sociais surdos pelo direito à língua de sinais, pelo direito a uma educação que abandone os seus mecanismos perversos de exclusão, e por um exercício pleno da cidadania, reconstruir essa história e uma nova experiência de liberdade, a partir da qual se torna possível aos surdos imaginarem outras representações para narrarem a própria história do que significa o ser surdo (2005, p. 29).

Trazer essas temáticas à discussão acadêmica contribui para a formação dos novos docentes, proporcionando ferramentas para que os(as) educandos(as) surdos(as) se identifiquem nessas transversalidades. Assim, terão como desenvolver suas potencialidades, a fim de reconstruir sua identidade, não apenas 
surdo ou surda, mas, também, com sua raça/etnia, seu gênero e condição sexual, classe social, entre outros aspectos.

A Constituição Federal de 1988, em seus artigos 205 e 206, garante a todos, sem distinção, o direito a uma educação pública, gratuita e de qualidade (BRASIL, 1988). Pesquisas, estudos e a luta da comunidade surda indicam a Escola Bilingue enquanto esse espaço de qualidade prevista na lei, pois, no que diz respeito ao desempenho dos educandos surdos, esse modelo, através do uso da Língua de Sinais como primeira língua e ambiente compartilhado com a própria comunidade surda, apresenta resultados mais satisfatórios que a inserção de surdos nas classes de ouvintes, em escolas comuns.

De fato, a Escola Bilíngue tem se mostrado como a melhor alternativa na educação de surdos e surdas, mas o questionamento é se com o foco apenas na questão linguística, ela pode instrumentalizar os(as) educandos(as) a se perceberem na sociedade, com todas as relações de poder que coexistem e intervir na realidade em que vivem de forma crítica, lúcida e responsável, especialmente em tempos atuais em que a comunidade surda precisa estar mais atenta ao cerceamento dos direitos que já foram conquistados com muita luta.

$\mathrm{O}(\mathrm{a})$ docente em sala de aula pode proporcionar um ambiente em que, mesmo nas suas diferenças, o(a) educando(a) surdo(a) se veja igualmente capaz e com sua opinião e experiências validadas - assim como todos da classe -, formando, dessa forma, sujeitos autônomos, críticos respeitosos em relação ao outro.

Os(as) surdos(as) precisam ter garantido não somente o acesso à escola, mas a sua permanência e sucesso educacional (SÁ, 2011). A sua permanência perpassa por se sentir capaz de resolver conflitos, e, para isso, a escola precisa discutir sobre o que é ser sujeito, surdo e ouvinte, e outras discriminações a que esteja vulnerável. A Língua de Sinais é uma ferramenta fundamental no que concerne à utilização de mecanismos contra a reprodução de identidades dominantes, deslegitimando a ideia de que outras devem ser subalternas e inferiores (SÁ, 2011). Esse empoderamento em sala de aula refletirá em sua interação social na população surda e em suas famílias.

Diante da falta de material bibliográfico que contemplasse a chave de busca que utilizamos em nossa coleta de dados, optamos por fazer uma revisão 
bibliográfica sobre educação numa perspectiva feminista, traçando paralelos com a surdez.

\section{Considerações finais}

Levando em consideração a ausência de pesquisas na temática da questão de gênero na Educação de Surdos, percebemos que a universidade tem focado a produção científica na área da surdez para aspectos linguísticos e de saúde. No entanto, entendemos que existem outros aspectos que perpassam o ser surdo além da sua língua.

A população surda não é homogênea: existem interseccionalidades que podem incidir sobre a vida das pessoas que fazem parte dessa população. A discriminação sofrida por ser um sujeito surdo é agravada se somada ao racismo, machismo e a LGBTfobia.

Diante da ausência de dados científicos sobre essas questões, e de como é a vivência dos(as) educandos(as) surdos(as) e as relações de gênero, mostra-se quão necessárias são as pesquisas para evidenciar as opressões na mesma intensidade ou não das pessoas ouvintes.

Os(As) pesquisadores(as) da área de Educação de Surdos precisam se apoiar em uma educação antidiscriminatória, por meio de um prática educacional baseada em pedagogias e teorias Feministas, cujo compromisso é contribuir para a formação de cidadãos(ãs) autônomos(as) e capazes de tomar decisões, analisando criticamente a realidade em que estão inseridos(as) e sendo capazes de combater dualidades impostas de feminino/masculino e ouvintismo/surdez, entre outras questões de sexualidade e gênero.

Com esta pesquisa, tornamos expostos que a área de surdez-gênerosexualidade deve ser incluída no rol de interesses dos(as) pesquisadores(as) em Educação Especial e Inclusão para rever e ressignificar suas respectivas pesquisas voltadas para a comunidade surda que. por muito tempo. foi espoliada e cerceada de direitos. Por fim, esperamos dos(das) educadores(as) a revisão das suas práticas educacionais no que tange a esses assuntos. 


\section{REFERÊNCIAS}

ANDERE, Maira Assaf; ARAUJO, Adriana Maria Procópio de. Aspectos de formação do professor de Ensino Superior de Ciências Contábeis: uma análise dos Programas de Pós-Graduação. Revista Contabilidade \& Finanças, v. 19, n. 48, p. 91-102, 2008. Disponível em: http://www.revistas.usp.br/rcf/article/view/34273/37005. Acesso em: 16 jun. 2019.

BOCCATO, Vera Regina C. Metodologia da pesquisa bibliográfica na área odontológica e o artigo científico como forma de comunicação. Rev. Odontol. Univ. Cidade São Paulo, v. 18, n. 3, p. 265-274, 2006. Disponível em: http://arquivos. cruzeirodosuleducacional.edu.br/principal/old/revista_odontologia/pdf/setembro_dez embro_2006/metodologia_pesquisa_bibliografica.pdf. Acesso em: 16 jun. 2019.

BRASIL. Constituição da República Federativa do Brasil. Brasília, DF: Senado Federal: Centro Gráfico, 1988, 292 p.

BRITO, Eliana Póvoas Pereira Estrela. Entre a aceitação e a fuga: a juventude negra em trânsito nos currículos escolares. Revista Exitus, v. 9, n. 4, p. 37-65, 2019. Disponível em: http://www.ufopa.edu.br/portaldeperiodicos/index.php/revistaexitus/ article/viewFile/1004/522. Acesso em: 16 jun. 2019.

CARVALHO, Maria Eulina P.; RABAY, Glória; BRABO, Tania Suely A. M.; FÉLIX, Jeane; DIAS, Alfrancio F. Direitos humanos das mulheres e das pessoas LGBTQI: inclusão da perspectiva da diversidade sexual e de gênero na educação e na formação docente. João Pessoa: Editora UFPB, 2017.

CORNACHIONE JR., Edgard Bruno. Tecnologia da educação e cursos de ciências contábeis: modelos colaborativos virtuais. Tese (Livre Docência). São Paulo: Faculdade de Economia, Administração e Contabilidade, Universidade de São Paulo, 2004.

GOMES, Nilma Lino. Educação, raça e gênero: relações imersas na alteridade. Cadernos Pagu, n.6/7, p. 62-82, 1996. Disponível em: https://periodicos.sbu. unicamp.br/ojs/index.php/cadpagu/article/view/1862. Acesso em: 16 jun. 2019.

KLEIN, Madalena; FORMOZO, Daniele de Paula. Gênero e surdez: reflexão e ação, Santa Cruz do Sul, v. 15, n. 1, p. 100-112, mar. 2008. ISSN 1982-9949. Disponível em: https://online.unisc.br/seer/index.php/reflex/article/view/225. Acesso em: 16 jun. 2019.

KRAUSE, Keli. Feminismos surdos, deficiências e políticas públicas. Anais do V Seminário Internacional Enlaçando Sexualidades, V Seminário Internacional Enlaçando Sexualidades, Salvador, 6 a 8 de setembro de 2017.

LOURO, Guacira Lopes. Gênero, sexualidade e educação: uma perspectiva pósestruturalista. Petrópolis, RJ: Vozes, 1997. 
LOURO, Gracira Lopes. Educação e Docência: diversidade, gênero e sexualidade. Formação Docente, Belo Horizonte, v. 3, n. 4, jan./jul, 2011. Disponível em: https://revformacaodocente.com.br/index.php/rbpfp/article/view/31/30. Acesso em: 16 jun. 2019.

MACEDO, Yuri Miguel; OLIVEIRA, Eduardo David; PEÇANHA, Cinézio Feliciano. A capoeira como referencial metodológico para enfrentamento do racismo. Revista da Associação Brasileira de Pesquisadores/as Negros/as (ABPN), v. 11, n. ed. esp., p. 174-187, out. 2019. Disponível em: http://abpnrevista.org.br/revista/index.php/ revistaabpn1/article/view/699. Acesso em: 16 jun. 2019.

MIRANDA, Viviane Marques. Surdez e racialidade: identidades em diálogo no espaço escolar? Revista da Fundarte, Montenegro, ano 17, n. 33, p.39-69, 2017. Disponível em: http://seer.fundarte.rs.gov.br/index.php/RevistadaFundarte/index. Acesso em: 16 jun. 2019.

PASSOS, Elizete; ROCHA, Nivea; BARRETO, Maribel. Gênero e Educação. In: VANIN, lole Macedo (org.). Ensino e Gênero: perspectivas transversais. Salvador: UFBA-NEIM, 2011. p.49-59.

PIZZANI, Luciana; SILVA, Rosemary Cristina da; BELLO, Suzelei Faria; HAYASHI, Maria Cristina Piumbato Innocentini. A arte da pesquisa bibliográfica na busca do conhecimento. Rev. Dig. Bibl. Ci. Inf., v. 10, n. 1, p. 53-66, 2012. Disponível em: https://periodicos.sbu.unicamp.br/ojs/index.php/rdbci/article/view/1896. Acesso em: 16 jun. 2019.

RIBEIRO, Djamila. Feminismo Negro para um novo marco civilizatório. SUR Revista Internacional de Direitos Humanos, n. 24, v.13, p. 99-104, 2016. Disponível em: https://sur.conectas.org/feminismo-negro-para-um-novo-marcocivilizatorio/. Acesso em: 16 jun. 2019.

RIBEIRO, Jessica Akemi Kawano. A lesbianidade e a surdez. Periodicus, Salvador. n. 7, v. 1, p. 179-191, 2017. Disponível em: https://portalseer.ufba.br/index.php/ revistaperiodicus/article/download/21550/14307. Acesso em: 16 jun. 2019.

SÁ, Nídia Regina Limeira de. Surdos: qual escola? Manaus: Editora Valer e Edua, 2011.

SANTOS, Ana Celia de Sousa. Pedagogia Feminista como possibilidade de construção de novas relações de gênero. Revista Artemis, v 14, n. 1, p. 174-182, 2012. Disponível em: https://periodicos.ufpb.br/ojs2/index.php/artemis/article/view/ 14300/8175. Acesso em: 16 jun. 2019.

SARDENBERG, Cecília M. B. Considerações introdutórias às Pedagogias Feministas. In: VANIN, lole Macedo (org.). Ensino e Gênero: perspectivas transversais. Salvador: UFBA-NEIM, 2011a. p.17-32.

SARDENBERG, Cecília M. B. Relações de gênero: uma breve introdução ao tema. In: VANIN, lole Macedo (org.). Ensino e Gênero: Perspectivas Transversais. Salvador: UFBA-NEIM, 2011b. p. 33-48. 
SARDENBERG, Cecília M. B. Caleidoscópios de gênero: Gênero e interseccionalidades na dinâmica das relações sociais. Mediações, Londrina, v. 20 n. 2, p. 56-96, jul./dez. 2015.

SILVA, Salete M. Gênero e Cidadania: questões para serem pensadas no quotidiano escolar. In: VANIN, lole Macedo. (org.). Ensino e Gênero: perspectivas transversais. Salvador: UFBA-NEIM, 2011. p. 125-138.

SKLIAR, Carlos. A surdez: um olhar sobre as diferenças. Porto Alegre: Mediação. 2005.

TEIXEIRA, Cynthia Moraes. Instituto Santa Terezinha: onde os surdos aprendem a ouvir e os mudos a falar. Monografia (Licenciatura em Pedagogia), Centro de Ciências e Humanidades, Universidade Presbiteriana Mackenzie, São Paulo, SP, 2008.

VANIN, Iole Macedo. Discutindo acerca da utilização de alguns recursos metodológicos no processo de ensino-aprendizagem não-discriminatório. In: VANIN, lole Macedo. (org.). Ensino e Gênero: perspectivas transversais. Salvador: UFBANEIM, 2011. p. 159-177.

WITCHS, Pedro Henrique. Gênero e Sexualidade na Educação de Surdos. Rev. Educ. Cult. Soc., v. 7, n. 1, p. 75-88, 2017. Disponível em: http://sinop.unemat. br/projetos/revista/index.php/educacao/article/view/2587. Acesso em: 16 jun. 2019. 